\title{
Plan de Estrategias para la Protección y Conservación de los Fuertes de Portobelo y San Lorenzo.
}

\section{Patricia $\mathrm{Cid}^{1,3,{ }^{*}}$ y Leonardo Casini ${ }^{2,3}$}

${ }^{1}$ Profesora e Investigadora, Facultad de Arquitectura y Diseño, Universidad Católica Santa María la Antigua de Panamá

${ }^{2}$ Investigador Asociado, Universidad Católica Santa María la Antigua de Panamá.

${ }^{3}$ Egresado de la Maestría en Restauración, Università degli Studi Roma Tre, Italia.

* Autor para correspondencia. Email: p.cid@,casinicidarchitetti.it; pcidl@usma.com.pa

Recibido: 22 de febrero de 2017 Aceptado: 04 de marzo de 2017

\begin{abstract}
.
The Strategy Plan for the Protection and Conservation of the Fortifications of Portobelo and San Lorenzo is a collaboration of the Santa Maria la Antigua Catholic University (USMA) to the National Directorate of Historical Heritage (DNPH) of the National Institute of Culture of Panama (INAC), in the search for instruments that allow the preservation and conservation of both national historical monuments, as well as the elimination of their inclusion in the List of World Heritage in Danger of the United Nations Educational, Scientific and Cultural Organization Culture (UNESCO).

The document is based on the observations and recommendations issued by the International Council on Monuments and Sites (ICOMOS) in February 2014, following its visit to Panama as an Advisory Mission to UNESCO, in view of the continuing deterioration structures of fortifications, advances in institutional arrangements in the planning of protection and management policies, and the need to create resources for the adoption of corrective measures and implementation of strategies of action, among others.

The Strategy Plan aims to be a resource for INAC and DNPH in which to rely on the definition of new strategies that allow to fulfill the mission to protect and conserve the Fortifications of Portobelo and San Lorenzo based on the deep understanding of its original historical - cultural attributes that transmit the Outstanding Universal Value (OUV) that own these architectural works and that are part of the World Heritage.

For this reason, a synergy has been created between the USMA and the DNPH to address the issue, where the authors of the project are experts in the field of Monumental Architectural Restoration and Heritage Protection and have an international experience in conservation and preservation of fortifications (ICOMOS 2014: 5, points 7 and 8).
\end{abstract}


Keywords. Antonelli; Architectural Heritage; UNESCO Tutelage; World Heritage in Danger; Monument

\section{Resumen.}

El Plan de Estrategias para la Protección y Conservación de los Fuertes de Portobelo y San Lorenzo es una colaboración de la Universidad Católica Santa María la Antigua (USMA) a la Dirección Nacional de Patrimonio Histórico (DNPH) del Instituto Nacional de Cultura de Panamá (INAC), en la búsqueda de instrumentos que permitan la preservación y conservación de ambos monumentos históricos nacionales ${ }^{1}$, así como, la eliminación de su inclusión en la Lista del Patrimonio Mundial en Peligro $(1)^{2}$ de la Organización de las Naciones Unidas para la Educación, la Ciencia y la Cultura (UNESCO).

El documento se basa en las observaciones y recomendaciones emitidas por el Consejo Internacional de Monumentos y Sitios (ICOMOS) en febrero del 2014 (2), después de su visita a Panamá en calidad de Misión Consultiva como organismo asesor de la UNESCO, ante la problemática del continuo deterioro de las estructuras de las fortificaciones, los avances en los acuerdos institucionales en la planificación de políticas de protección y gestión, y la necesidad de crear recursos para la adopción de medidas correctivas y de implementación de estrategias de acción, entre otros.

El Plan de Estrategias pretende ser un recurso para el INAC y la DNPH en el cual, apoyarse para la definición de nuevas estrategias que permitan cumplir con la misión de proteger y conservar los Fuertes de Portobelo y San Lorenzo fundamentándose en la comprensión profunda de sus atributos histórico - culturales originales que transmiten el Valor Universal Excepcional (VUE) que poseen estas obras arquitectónicas y que forman parte del Patrimonio de la Humanidad.

Para esto, se ha creado una sinergía entre la USMA y la DNPH para afrontar el tema, donde los autores del proyecto son especialistas en el ámbito de la Restauración Arquitectónica Monumental y en la Tutela de Monumentos Históricos y cuentan con experiencia en la conservación y preservación de fortificaciones $(2)^{3}$.

Palabras clave. Antonelli; Patrimonio Arquitectónico; Tutela UNESCO; Patrimonio Mundial en Peligro; Monumento.

\section{Introducción}

En 1941, las Fortificaciones de Portobelo y San Lorenzo fueron reconocidas y declaradas como "Monumentos Históricos Nacionales" por la Ley N68; mientras que, en 1976 la concepción de Portobelo se amplía a "Conjunto Monumental Histórico" por la Ley N91. La inscripción de ambas

\footnotetext{
${ }^{1}$ El Castillo de San Lorenzo de Chagres y las ruinas históricas del Distrito de Portobelo junto con el edificio de la Aduana fueron declarados Monumentos Históricos Nacionales por la Ley Nº 68 del 11 de junio de 1941, Artículo 1.

2 Decisión 36 COM 7B.102

${ }_{3}^{3}$ Así como solicitado, en los Puntos 7 y 8 de las Recomendaciones de ICOMOS.
} 
Invest. pens. crit. (ISSN 1812-3864)

Vol. 5, No. 1, enero-abril 2017

pp. $41-68$

fortificaciones a UNESCO como Patrimonio Mundial de la Humanidad y en una única propiedad, en cambio, se da 4 años más tarde, bajo los criterios de evaluación del VUE: (i) y (iv) (3) ${ }^{4}$.

De acuerdo con la "Evaluación del Estado de Conservación de la Propiedad (Assessment of the State of Conservation of the Property)" de ICOMOS $(2)^{5}$ en el 2014 y con los "Análisis y Conclusiones del Centro del Patrimonio Mundial, ICOMOS e ICCROM (Analysis and Conclusions of the World Heritage Centre, ICOMOS and ICCROM)" (4) emitidos por el Comité del Patrimonio Mundial un año después, en la 39ma Sesión de la Convención para la Protección del Patrimonio Mundial Cultural y Natural; en ambos documentos se observa que, a pesar de que, las fortificaciones aún conservaban la condición de "integridad" (5) en gran parte de sus estructuras, éstas continuaban a verse amenazadas por una serie de factores enunciados a lo largo de los últimos 10 años y que inclusive en la actualidad, aumentan la posibilidad de perder la condición de "autenticidad" de sus atributos si no se toman medidas actuativas inmediatas.

El presente proyecto, por una parte, se concentra en ahondar en la comprensión del VUE atribuido a los Fuertes de Portobelo y San Lorenzo a través del estudio histórico de sus características originales y posteriores, así como, de las relaciones políticas, militares, arquitectónicas y constructivas que comprenden estos bienes monumentales y que expresan la "autenticidad" de sus valores. Y por otra, en determinar diversas estrategias de tutela orientadas a la protección y conservación de las estructuras actuales para la preservación de los bienes monumentales y del Patrimonio Mundial de las costas caribeñas de Panamá.

\section{Antecedentes Actuativos de Protección y Conservación}

Las Fortificaciones de Portobelo y San Lorenzo, localizadas en la Costa Atlántica de Panamá, han pasado por diversos planteamientos a lo largo de los años con la intención de protegerlas, conservarlas y valorizarlas. Las primeras leyes de tutela se dan en 1941 con la declaración de ambos fuertes como "Monumentos Históricos Nacionales" y con la asignación del Departamento de Bellas Artes del Ministerio de Educación, como encargada de su conservación. Antes de esto, las leyes que se crean son sólo de tipo administrativo referentes a la destinación de fondos para la mantención de los sitios. A partir de los años 60 y con la creación del Instituto Panameño de Turismo 9 (IPAT) y del Instituto Nacional de

${ }^{4}$ Criterios de Selección UNESCO de los Bienes con Valor Universal Excepcional para un monumento, conjunto de edificaciones o sitio:

(i) Represent a unique artistic or aesthetic achievement, a masterpiece of the creative genius

(iv) Be among the most characteristic example of a type of structure, the type representing an important cultural, social, artistic, scientific, technological or industrial development

5 Págs. 18-20

${ }^{6}$ Núm. 46, pág. 93 y 94

${ }^{7}$ Definiciones de Integridad y Autenticidad. Capítulo II.E , Art. 79 - 95, pág. 17 - 19

${ }^{8}$ Ley 67 del 11 de junio de 1941. Título: "Por la cual se dictan varias disposiciones relacionadas con los Monumentosy Objetos Arqueológicos". Dictada por: la Asamblea Nacional. Gaceta Oficial: 08538

${ }^{9}$ Con el Decreto Ley 22 del 15 de septiembre de 1960, se crea el Instituto Panameño de Turismo, primera entidad nacional dedicada a "proteger, mantener, reconstruir y dar a conocer sitios de interés histórico, así como lugares de belleza natural o de importancia cientifica...” (cap. II, art. 3, letra h) 
Cultura $^{10}$ (INAC) en 1974, Panamá se concentra en crear el inicio de una legislación coherente con el reconocimiento, protección y salvaguarda de los bienes históricos nacionales y con un primer proceso de sistemación, organización normativa e incentivos para la restauración y puesta en valor de los primeros bienes nacionales identificados como tales. En 1976, Portobelo es declarado "Conjunto Monumental Histórico" "11 que, además del conjunto de fortificaciones de los siglos XVI al XVIII, incluye el reconocimiento de su centro histórico, sus bienes arquitectónicos y su patrimonio socio cultural; y se crea también, el "Parque Nacional de Portobelo" que reconoce la relación ecológico cultural del conjunto y su cualidad de convivencia entre el patrimonio natural y el patrimonio construido ${ }^{12}$.

La jurisdicción del territorio donde se encuentran ubicadas ambas Fortificaciones, ha pasado por varias fases políticas. El siglo XX se inicia para Panamá, por un lado, con su separación definitiva de Colombia, y por otra, con la inclusión de una jurisdicción norteamericana en una parte del territorio nacional dedicada a la construcción, administración y defensa del Canal Interoceánico ${ }^{13}$; dejando de este modo, a Portobelo a cargo de la custodia panameña, y a San Lorenzo, de la custodia de los Estados Unidos a través de la Isthmian Canal Commission ${ }^{14}$ la cual, se ocupó principalmente del mantenimiento y limpieza del sitio y de las estructuras. Esto se mantuvo así, hasta 1979 cuando el territorio donde está ubicado el Fuerte de San Lorenzo, revierte a Panamá de acuerdo con el Tratado Torrijos - Carter firmado dos años antes. Gracias a este pasaje, Panamá decide presentar a finales del mismo año, las Fortificaciones de la Costa Caribeña de Panamá: Portobelo y San Lorenzo $0^{15}$ ante la UNESCO para solicitar su tutela internacional y el reconocimiento de estos bienes como Patrimonio de la Humanidad.

Los años 70 y 80 fueron significativos en la creación de instrumentos actuativos que permitieran la recuperación de la edilicia histórica panameña. Se solicita la asesoría internacional de dos importantes y

\footnotetext{
${ }^{10}$ Ley 63 del 6 de junio de 1974. Título: "Por la cual se crea el Instituto Nacional de Cultura” y donde además, se crea la Dirección de Patrimonio Histórico. Dictada por: el Consejo Nacional de Legislación. Gaceta Oficial: 17622

${ }^{11}$ Ley 91 del 22 de diciembre de 1976. Título: "Por la cual se regulan los Conjuntos Monumentales Históricos de Panamá Viejo, Portobelo y el Casco Antiguo de la Ciudad de Panamá”. Dictada por: el Consejo Nacional de Legislación. Gaceta Oficial: 18252

12 Art.15, Ley 91/1976: "Créase como Parque Nacional de Portobelo, el espacio territorial que circunda la ciudad de Portobelo, que con ella integra una sola unidad de paisaje y refleja una relación ecológico - cultural."

13 Tratado Hay - Bunau Varilla establecido por Panamá y Estados Unidos, el 18 de noviembre de 1903.

${ }^{14}$ Entidad que se llamó: Isthmian Canal Commission (1904 - 1979), Panama Canal Commission (1979 - 1997), Autoridad del Canal de Panama (1997 - hoy)

${ }^{15}$ El documento se presenta el 26 de diciembre de 1979, con el N¹35 y obtiene su aprobación en 1980, en la 4ta Sesión del Comité del Patrimonio Mundial, en la Convención para la Protección del Patrimonio Mundial Cultural y Natural celebrado en París, Francia (CC-80/CONF.016/10)
} 
reconocidas figuras en la investigación histórica y la restauración monumental: el historiador español, el Dr. Juan Manuel Zapatero ${ }^{16}$, y el arquitecto mexicano Carlos Flores Marini ${ }^{17}$.

En 1971, el Dr. Zapatero entrega a la OEA y al IPAT, el primer Estudio Asesor para la Restauración y Rehabilitación Museográfica de las Fortificaciones de Portobelo, basado en una profunda y exhaustiva investigación histórica; mientas que, el Arq. Flores Marini desarrolla los Planes Maestros para la puesta en valor del Casco Antiguo de la Ciudad de Panamá (1972), del Sitio Arqueológico de Panamá Viejo y del Complejo de Fortificaciones de Portobelo $\left(1974\right.$ - 1977) (6) ${ }^{18}$.

La intervención al Centro Histórico de Portobelo fue organizada a través del Plan Piloto Portobelo $(7)^{19}$, por el Dr. arquitecto José Manuel González Valcárcel y el arquitecto Francisco Landínez Gutiérrez, ambos españoles y en calidad de expertos de la OEA. El Plan contemplaba inicialmente el traslado de la población (600 personas aprox.), la recuperación del trazado urbanístico original y la restauración de sus bienes arquitectónicos a través de la creación de un sitio protegido y destinado al turismo que conservase sus cualidades y características históricas a actuar como una "ciudad museo". Este planteamiento fracasó y en su lugar, se decidió optar por la integración cultural de sus pobladores al proyecto, la lectura del trazado urbano, el inventario de los bienes arqueológicos y arquitectónicos presentes y a la restauración de sólo los monumentos principales.

A finales de los años 70 e inicios de los 80, con la reversión del territorio norteamericano, la nominación UNESCO y el interés en restaurar y revalorizar los bienes monumentales, la Dirección de Patrimonio Histórico del INAC llama nuevamente al Dr. Juan Manuel Zapatero, para realizar una investigación que sustentase los criterios de VUE del Fuerte de San Lorenzo e individuase una serie de estrategias de protección y conservación para éste: el Estudio Asesor para la Restauración y Rehabilitación Museográfica del Castillo San Lorenzo el Real de Chagre (1981). La información recaudada serviría de base al Proyecto de Restauración y a la Rehabilitación Museográfica que formarían parte del Plan de Atractivo Turístico del INAC, que contaba además, con el apoyo de la Dirección General de Relaciones Culturales, el Ministerio de Asuntos Exteriores de España, el Comité del Patrimonio Mundial de la UNESCO y la Junta del Plan de Desarrollo, CODERO, de la ciudad de Colón $(8)^{20}$.

\footnotetext{
${ }^{16}$ Director de la Sección de Ultramar del Servicio Histórico Militar español y Doctor en Historia. Asesor para la restauración de fortalezas en España, Puerto Rico, Perú, Colombia, Honduras y Venezuela.

${ }_{17}$ Reconocido por su importante labor en el patrimonio monumental de México, República Dominicana, Brasil, Venezuela y Colombia, y por su participación en la redacción de la Carta de Venecia de 1964, las Normas de Quito de 1967 y la Resolución de Santo Domingo de 1974.

18 Pág. 174. Además, de 1976 a 1982, la “Dirección de Turismo Cultural” del IPAT será la encargada del manejo del Conjunto Monumental de Portobelo (Art. 55, Ley 91/1976)

19 Págs. 147 - 151.

20 Pág. 35.
} 
En 1982, con la promulgación de la Ley N¹4 donde "se dictan medidas sobre la custodia, conservación y administración del Patrimonio Histórico de la nación”, se inicia un importante período de intervenciones de tipo restaurativo y conservativo para las construcciones monumentales más representativas del país. Los primeros trabajos por parte del gobierno panameño en San Lorenzo, se efectuaron entre 1982 y 1984 , financiados por el Banco Mundial y el gobierno español.

Con la llegada de los años 90, se reaviva el interés por el rescate de las Fortificaciones y se reinicia con un nuevo período de planteamientos en la tutela y recuperación de estos sitios orientados a la conmemoración de los 500 años del descubrimiento de América. El Plan de Acción de Portobelo (1990 - 1992) comprendía intervenciones inmediatas sobre las fortificaciones y en tres de las edificaciones más representativas del Centro Histórico: la Aduana de Portobelo, la Casa Rodríguez y la Iglesia de San Felipe (sólo el techo).

En 1992, Panamá recibe una delegación de expertos de ICOMOS, donde se evalúa el estado de conservación de los Fuertes de Portobelo y San Lorenzo. El Reporte recibido por UNESCO (9) ${ }^{21}$ y comunicado en la $17^{\circ}$ Sesión celebrada en Colombia, informa sobre las condiciones "aceptables" del Fuerte de San Lorenzo y sobre la "presión" que vive Portobelo ante el crecimiento de su población dentro de un área monumental y ante un sistema de infraestructuras deficientes que afectan a las estructuras de las fortificaciones. Además de esta problemática, se comunica sobre la realización del Plan de Acción de Portobelo:

"[...]The mission concluded that the Fortress of San Lorenzo was in an acceptable state of conservation, although stone conservation requires some special attention. The city of Portobelo is under pressure from increased population and deficient infrastructure. An action plan was drawn up for the execution of the necessary archeological survey before construction works are undertaken in the town. Underwater excavations should not be considered as a priority."

En este período, el INAC, el IPAT y el INRENARE ${ }^{22}$ realizan diversos planes de manejo importantes para Portobelo. Entre ellos: el Plan de Manejo del Parque Nacional de Portobelo (1992 - 1994) con la colaboración del Instituto para la Conservación de la Naturaleza (ICONA) de España, donde la ciudad histórica viene clasificada como la Zona 4: Histórica - Monumental; el Plan Maestro de Desarrollo Turístico (1994) a escala nacional donde se promueven los atractivos del Parque Nacional de Portobelo; y el Plan de Ordenamiento Territorial del Parque Nacional de Portobelo y el Conjunto

\footnotetext{
21 Pág. 23

22 Instituto Nacional de Recursos Naturales Renovables, creado por la Ley 1 del 3 de febrero de 1994 que con la Ley 41 de julio de 1998 cambia a Autoridad Nacional del Ambiente (ANAM). Actualmente, Ministerio del Ambiente (MiAmbiente) por la Ley 8 del 25 de marzo de 2015.
} 
Invest. pens. crit. (ISSN 1812-3864)

Vol. 5, No. 1, enero-abril 2017

pp. 41-68

Monumental Histórico de Portobelo (1999) ${ }^{23}$, donde también participa el MIVI y está dirigido, entre algunos de sus objetivos, a fortalecer la conservación del Conjunto Monumental y lograr un desarrollo turístico sostenible y cónsono con el uso especial del Parque.

Durante la segunda mitad de los años 90, inicia la organización para la reversión total del territorio ocupado por la antigua Zona del Canal y sus bases militares norteamericanas. En 1997, se establece el Plan Regional para el Desarrollo de la Región Interoceánica y el Plan General de Uso, Conservación y Desarrollo del área del Canal donde se incluye la protección del Fuerte de San Lorenzo, clasificado dentro de la Categoría I - Areas Silvestres Protegidas de la Subregión 1 - Atlántico Oeste. Se define un bosque protector con un área paisajística con fines turísticos y ecoturísticos donde San Lorenzo es reconocido como un área valiosa por sus recursos marinos, costeros e históricos. A esta área se le llamará "Bosque Protectory Paisaje Protegido San Lorenzo".

Con la Ley 41 de 1 de julio de 1998, el área de San Lorenzo y su Bosque Protector como el Parque Nacional de Portobelo pasan a formar parte del Sistema Nacional de Areas Protegidas (SINAP) a cargo de la ANAM y desde el 2015, por el Ministerio del Ambiente ${ }^{24}$.

Posteriormente, el desarrollo urbanístico y el ordenamiento territorial del sector Atlántico fueron regulados por el MIVI a través de la integración del Plan Regional y el Plan General de las áreas revertidas (1997) y comprendidos en el Plan de Desarrollo Urbano de las Areas Metropolitanas del Pacífico y el Atlántico ${ }^{25}$, que inicia a regir con el Decreto Ejecutivo $\mathrm{N}^{\circ} 205$ del 28 de diciembre del 2000.

El patrimonio subacuático de ambos territorios, en cambio, se acoge a las observaciones realizadas en la “Convención sobre la Protección del Patrimonio Cultural Subacuático" de la UNESCO, efectuada en su $31^{\circ}$ reunión $^{26}$ (2001) las cuales, son ratificadas por la Ley 32 del 26 de marzo del $2003^{27}$. Entre sus objetivos destacan el no permitir la explotación comercial de estos bienes y el acceso al público para su observación y/o documentación con la finalidad de, favorecer a la sensibilización, el reconocimiento y su protección.

La promoción turística y las actividades culturales en Portobelo y San Lorenzo siguen el Plan Maestro de Turismo Sostenible de Panamá 2007 - 2020 (PMTS) creado por el IPAT ${ }^{28}$ con la colaboración del grupo de consultoría español, Tourism and Leisure - Europraxis Consulting, la ANAM, el BID, el PNUD, entre otros; donde a través del turismo cultural y científico como línea de producto a ofrecer, se pretende valorizar y conservar el patrimonio cultural y natural nacional. El Plan plantea como una de las

\footnotetext{
${ }^{23}$ Modificado por el Decreto Ejecutivo 1366 del 28 de diciembre de 2012, del Ministerio de Economía y Finanzas. Gaceta Oficial: 27197

${ }^{24}$ Ley 8 del 25 de marzo de 2015 que crea el Ministerio del Ambiente.

25 Actualmente, este Plan se encuentra en revisión y actualización.

${ }^{26}$ Reunión celebrada del 15 de octubre al 3 de noviembre de 2001, en París - Francia.

${ }^{27}$ Con la adopción de las observaciones de la Convención, la Ley 14 de 1982 viene modificada por la Ley 58 del 7 de agosto de 2003, de la Asamblea Legislativa. Gaceta Oficial: 24864

${ }^{28}$ Un año más tarde, con el Decreto Ley 4 del 27 de febrero de 2008, dictado por el Consejo de Gabinete, se crea la Autoridad de Turismo de Panamá que remplazará al IPAT. Gaceta Oficial: 25989. Y viene reglamentada por el Decreto Ejecutivo 82 del 23 de diciembre de 2008, del Ministerio de Comercio e Industrias. Gaceta Oficial: 26213
} 
Invest. pens. crit. (ISSN 1812-3864)

Vol. 5, No. 1, enero-abril 2017

pp. 41-68

8 estrategias turísticas, la conservación del medio ambiente y la adecuación de las Areas Protegidas para este uso, y organiza los destinos turísticos del país en 8 regiones de desarrollo. El Fuerte de San Lorenzo y su Bosque Protector se encuentran localizados en la Región Turística $6^{29}$; mientras que, Portobelo en la Región Turística $7^{30}$ que además, es indentificada en la selección de destinos turísticos prioritarios. De acuerdo con la programación del PMTS, a partir del 2015, en San Lorenzo se pretende alcanzar un alto nivel de intensidad en las actividades de desarrollo turístico, y en Portobelo, a partir del 2017.

\section{Problemática Actual}

En diciembre del 2010, el poblado de Portobelo es seriamente afectado por deslizamientos provenientes de la zona montañosa provocados por las fuertes lluvias $(10)^{31}$. Principalmente, el Fuerte de Santiago, ubicado al ingreso del poblado, es el mayor afectado al sufrir algunas pérdidas y daños en su parte posterior colindante con la carretera, así como, en sus estructuras interiores a causa del avance del terreno, de troncos y de piedras. (ver Figura 1)



Figura 1. Fuerte de Santiago afectado por los deslizamientos, Portobelo

Fuente: Periódico El Panamá América, publicada el 23 sept. 2011

\footnotetext{
${ }^{29}$ Destino 6.3 (Puerto de Colón): "Situado en la costa atlántica de Panamá, este amplio destino se conforma en torno al conglomerado urbano de la Ciudad de Colón y la Zona Franca, el sector de las esclusas de Gatún y el área litoral conocida como Costa Abajo de Colón... Ciudad de Colón tiene interesantes valores urbanos y arquitectónicos que merecen ser rescatados y limita con el Paisaje Protegido Isla Galeta, además de facilitar el acceso al Bosque de Protección y Paisaje Protegido San Lorenzo donde se encuentra el Fuerte español del mismo nombre declarado Patrimonio de la Humanidad por la UNESCO, el Parque Nacional Chagres y el Área Recreativa Gatún..."

${ }^{30}$ Destino 7.1 (Portobelo - Santa Isabel): "Zona litoral y de la costa del Caribe panameño que se distingue por su bistoria con testimonios como el Conjunto Monumental Portobelo, Sitio Patrimonio de la Humanidad y la cultura afro, con sus tradiciones y gastronomía vigentes, que se complementan con la naturaleza conservada del Parque Nacional del mismo nombre..."

${ }^{31}$ El Informe de Panamá sobre el Estado de Conservación de la Propiedad, del 11 de febrero del 2011, comunicaba los daños apenas sufridos: "...the majority of the damages occurred in Portobelo's Fort Santiago, where landslides affected already damaged structures, destroyed 30 meters of wall, structures and drains collapsed and a significant portion of the central plaza of the fortification was covered by 1300 cubic metres of mud and trees...."
} 
Invest. pens. crit. (ISSN 1812-3864)

Vol. 5, No. 1, enero-abril 2017

pp. 41-68

El Fuerte de Santiago de la Gloria construido en las faldas de la montaña y único vestigio del proyecto de Battista Antonelli y el más antiguo de las estructuras del lugar, en cambio, sufrió menos daños, ya que, los deslizamientos se produjeron en uno de sus costados como se aprecia en la fotografía a continuación. (ver Figura 2)

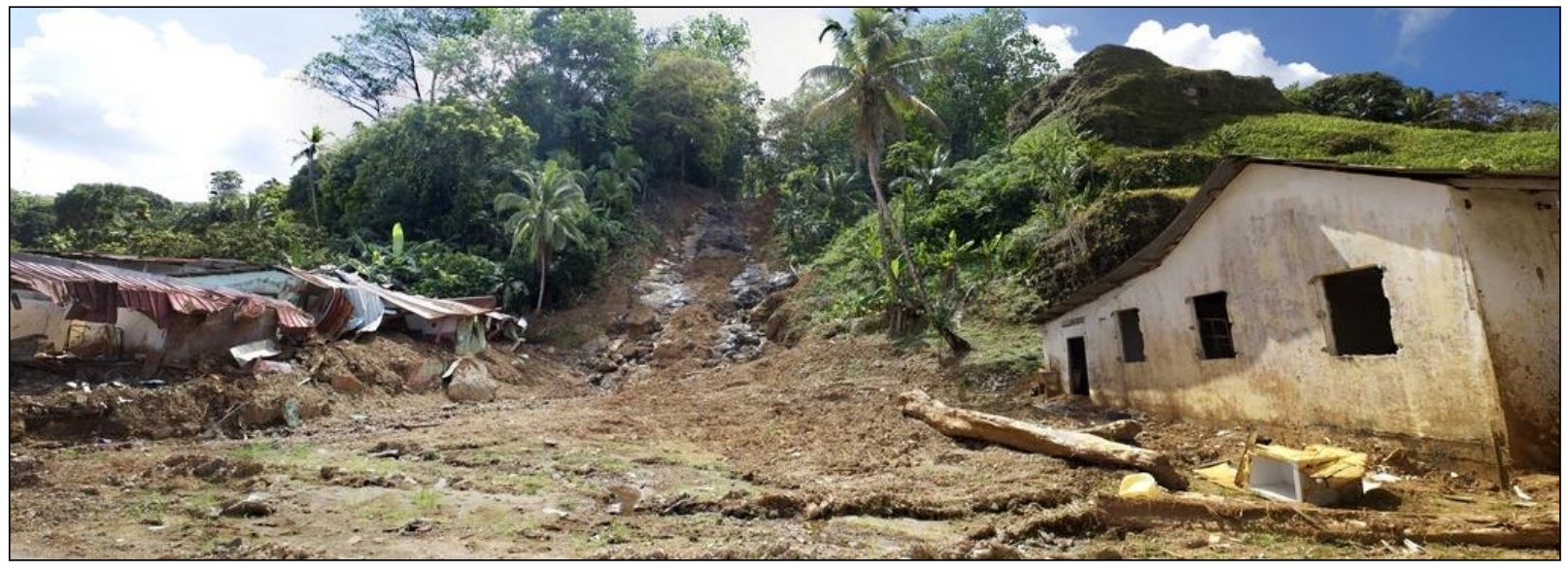

Figura 2. Fuerte de Santiago de la Gloria (derecha, en alto)

Fuente: Gaspar Serrano, publicada en Flickr, el 12 febr. 2011

Otro de los afectados fue el Fuerte de San Jerónimo que, a causa de la crecida de la Quebrada Guinea y del fuerte impacto de las corrientes sobre las estructuras ya deterioradas, ocasionó el colapso de un sector de sus muros. (ver Figura 3)

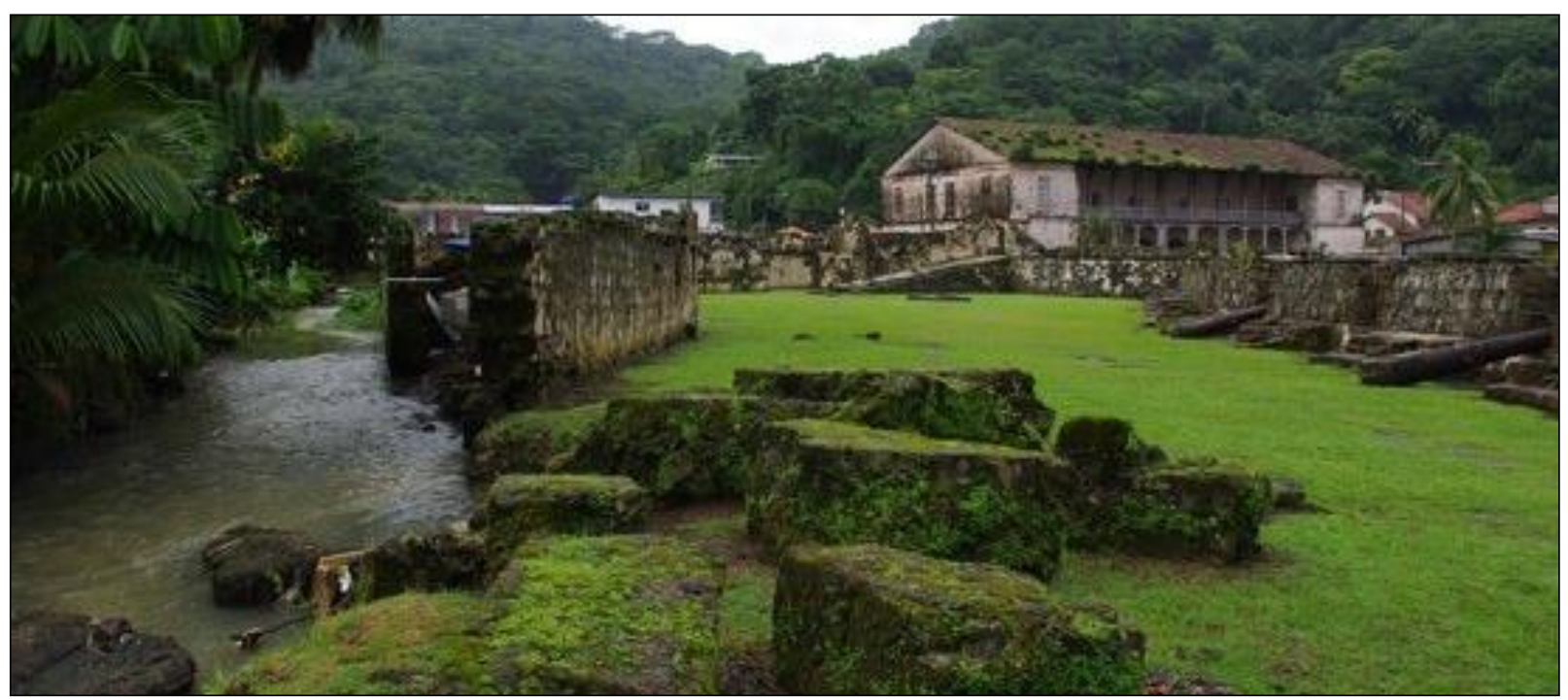

Figura 3. Colapso de la estructura muraria en el Fuerte de San Jerónimo por la Quebrada Guinea.

Fuente: TripAdvisor España 
Invest. pens. crit. (ISSN 1812-3864)

Vol. 5, No. 1, enero-abril 2017

pp. 41-68

Ante lo ocurrido, en la Reunión $35^{\circ}$ del WHC (11) ${ }^{32}$, UNESCO expresa su evaluación como el resultado de una práctica inadecuada en las intervenciones de tipo conservativo realizadas a las Fortificaciones hasta ese momento:

"[...]The heavy rains and resulting landslide also demonstrated that previously undertaken conservation works were inadequate and did not contribute significantly to the property's conservation [...]"

Adicional a esto, se suman los Reportes de Monitoreo a las fortificaciones, efectuados por ICOMOS en el 2001 y el 2010 donde se concluye que los factores que han afectado a la Propiedad en los últimos 10 años, han sido los siguientes ${ }^{33}$ :

“a) Deterioro y destrucción de la estructura de la propiedad por factores ambientales, falta de un programa de mantenimiento, así como, por el agua contaminada;

b) Erosion;

c) Ausencia de políticas de manejo incluidas en planes de manejo;

d) Desarrollo urbano incontrolado;

e) Presiones del turismo (en particular en Portobelo);

f) Lluvias torrenciales."

El estado de emergencia que se produce y la falta de recursos inmediatos (económicos, de planificación y de intervención) para resolver adecuadamente esta problemática, causan que la propiedad UNESCO: “Fortificaciones de la Costa Caribeña de Panamá: Portobelo y San Lorenzo", sea inscrita en la Lista del Patrimonio Mundial en Peligro (12) ${ }^{34}$ (1), en el 2012. Para cumplir con las condiciones de protección y conservación de un bien monumental UNESCO, se solicita a Panamá adoptar las siguientes medidas $(12)^{35}$ :

“a) La aprobación y la plena aplicación de un plan de emergencia, una evaluación exhaustiva de los riesgos estructurales y mecánicos, una estrategia preventiva de conservación y medidas de mantención en San Lorenzo y Portobelo,

\footnotetext{
32 Pág. 265

33 Conservation issues presented to the World Heritage Committee in 2011:

"a) Deterioration and destruction of the fabric of the property by environmental factors, lack of a maintenance program, as well as polluted water; b) Erosion; c) Absence of management policies included in management plans; d) Uncontrolled urban development; e) Tourism pressures (in particular at Portobelo); f) Torrential rains."

34 Pág. 173

35 Pág. 174, n. 7: "Adopts the following Desired state of conservation for the property, for its future removal from the List of World Heritage in Danger: a) The approval and full implementation of an emergency plan, a comprehensive assessment of structural and mechanical risks, preventative conservation strategy and maintenance measures at San Lorenzo and Portobelo, b) National laws and policies for the conservation of built heritage at San Lorenzo and Portobelo defined and in place, c) Long-term consolidation and conservation through annual plans for the components of the inscribed property ensured, d) The operational and participatory management system, including its related public use plan, approved and implemented, e) The Management Plan fully integrated within territorial and urban development plans, f) Encroachments and urban pressure adequately controlled, g) The boundaries and buffer zone of all component parts of the World Heritage property precisely clarified, b)Budgets for the preparation, implementation and follow-up of the management structures and conservation measures secured;"
} 
Invest. pens. crit. (ISSN 1812-3864)

Vol. 5, No. 1, enero-abril 2017

pp. $41-68$

b) La aplicación al sitio de leyes y politicas nacionales para la conservación del patrimonio construido en San Lorenzo y Portobelo,

c) La consolidación y conservación a largo plazo a través de planes anuales garantizados para los componentes de los bienes inscritos,

d) La aprobación y aplicación del sistema operativo y de gestión participativa, incluido su plan de uso público,

e) El Plan de Gestión plenamente integrado en los planes de desarrollo territorial y urbano,

f) Las invasiones y la presión urbana adecuadamente controladas,

g) Los límites y la rona de amortiguación de todos los componentes del Bien del Patrimonio Mundial se aclararon con precisión,

b) Los presupuestos para la preparación, ejecución y seguimiento de las estructuras de gestión y medidas de conservación garantizadas;"

Un año más tarde, Panamá presenta en su Informe sobre el Estado de Conservación de sus Propiedades UNESCO: un Plan de Gestión para las dos propiedades de tipo cultural inscritas al cual, llamará Plan de Gestión del Patrimonio Mundial UNESCO de Panamá: Sitio Arqueológico de Panamá Viejo y Casco Antiguo de Panamá (C-790bis) y Fortificaciones del Mar Caribe de Portobelo y San Lorenzo (C-135) ${ }^{36}$; una comunicación sobre las intervenciones realizadas al Fuerte de Santiago (sólo limpiezas y mantención del sitio. No se efectuaron operaciones de consolidación estructural); una investigación sobre las condiciones del subsuelo en las áreas afectadas; estrategias para la prevención de nuevos deslizamientos y una propuesta de construcción de un muro de contención para evitar el riesgo de colapso y deslizamientos hacia el Fuerte de Santiago.

En enero del 2014, Panamá presenta a UNESCO: el Emergency Plan for the Property C135 Fortifications on the Caribbean Side of Panama: Portobelo - San Lorenzo ${ }^{37}$, las intervenciones realizadas para estabilizar las áreas afectadas por los deslizamientos del 2010 y las evaluaciones y medidas adoptadas para evitar nuevos colapsos.

A finales de febrero, consultores de ICOMOS son enviados nuevamente, para evaluar el caso de las Fortificaciones de Portobelo y San Lorenzo. Su visita $(2)^{38}$ consiste en analizar el estado de conservación de la propiedad, recomendar la formulación de un Plan de Emergencias, asesorar en la identificación de medidas necesarias para controlar la presión del crecimiento urbano, evaluar las intervenciones en curso y recomendar la implementación de un sistema de gestión eficaz y un Plan de Manejo factible. Como

\footnotetext{
${ }^{36}$ El Plan de Gestión de los Sitios UNESCO de Panamá es aprobado por la Resolución N¹86 de la DNPH del INAC, del 12 de septiembre del 2013.

${ }^{37}$ Aprobado por la Resolución N62 de la DNPH del INAC, marzo 2014.

38 Pág. 10
} 
Invest. pens. crit. (ISSN 1812-3864)

Vol. 5, No. 1, enero-abril 2017

pp. $41-68$

resultado de la evaluación, se emiten 18 recomendaciones ${ }^{39}$ para que se implementen las siguientes medidas correctivas urgentes:

1. Finalizar de manera urgente, el proceso de adopción del Plan de Emergencia a través de una resolución de la DNPH $H^{40}$.

2. Comenzar la implementación sistemática de las acciones identificadas en el Plan de Emergencia para asegurar que el actual estado progresivo de deterioro de la propiedad Portobelo - San Lorenzo, sea adecuadamente abordado. Concluir su aplicación para septiembre de 2015 de conformidad con el calendario adoptado para las medidas correctivas ${ }^{41}$.

3. Continuar con la implementación de acciones urgentes incluidas en el Plan de Conservación y Protección establecido por el Plan de Gestión del Patrimonio Mundial UNESCO para la propiedad Portobelo - San Lorenzo en Panamá ${ }^{42}$. Debe darse prioridad a:

a. Actualización de los reglamentos de protección de la UNESCO mediante un proyecto de ley para proteger la propiedad y sus zonas de amortiguamiento terrestre y marítimo.

b. Actualización del marco técnico y normativo concluyendo la elaboración de una ley sobre las funciones y autofinanciación del Patronato Portobelo - San Lorenzo.

c. Reorganización del marco de trabajo relacionado con el patrimonio para que sea más simple y lograr una mayor eficiencia: revisión de las responsabilidades administrativas; elaboración de normas que garanticen una protección eficiente de la propiedad y de su Valor Universal Excepcional; aplicación de la capacidad de gestión del INAC y del Patronato; autosostenibilidad del plan del Patronato; creación de una oficina técnica de conservación con personal especializado;

d. Rehabilitación de edificios históricos amenazados o deteriorados en Portobelo y San Lorenzo: estudios integrales sobre riesgos estructurales y mecánicos; plan de emergencia para la protección y conservación de las fortificaciones; consolidación urgente de elementos amenazados de pérdida;

\footnotetext{
39 Traducción por los autores del ICOMOS Advisory Mission's Report 2014, p. 4 - 7

${ }^{40}$ El Plan de Emergencias enviado a UNESCO en enero del 2014, es adoptado por Panamá en el mes de marzo a través de la Resolución 62/2014, ya antes mencionada

${ }^{41}$ La implementación del Plan de Emergencia quedó suspendida durante el 2014, debido al proceso de cambio de gobierno en el país y de consecuencia, el cambio de directivos y funcionarios a nivel institucional (SOC Panama’s Report. January 24th, 2015. N4 - 'Response about the Decision of the World Heritage Committee 38 COM 7a.20”). Por esta razón, las intervenciones que se realizaron en el 2014 fueron de menor escala: limpieza, mantención y consolidaciones puntualizadas. Durante el 2015, se fijaron objetivos de organización, coordinación y programación entre la DNPH y el PPSL para la implementación del Plan estimada para el 2016 (13) ("Proposed Time Frame to accomplish the Corrective Measures 2016 - 2019. Phase 1", p.25).

${ }^{42}$ Los datos actualizados sobre las acciones realizadas durante el 2016 y en respuesta a las observaciones de ICOMOS fue presentado por la DNPH del INAC, en el SOC Panama’s Report de enero 2017.
} 
Invest. pens. crit. (ISSN 1812-3864)

Vol. 5, No. 1, enero-abril 2017

pp. 41-68

intervenciones de consolidación inmediatas y prevención de riesgos; limpieza general y tratamiento de macro y micro flora;

e. Plan de rehabilitación y preservación ambiental del entorno de la propiedad para el control de las presiones del crecimiento urbano; elaboración de un Plan sobre la interpretación y protección del complejo de fortificaciones incluyendo la Babia de Portobelo y el acceso al Rio Chagres como espacios defensivos, permitiendo la rehabilitación tanto del patrimonio bistórico como del natural; cercas para evitar el vandalismo.

4. Concluir la definición y aprobación legal de los límites y de la zona de amortiguamiento de cada componente de la propiedad del Patrimonio Mundial para controlar las presiones de desarrollo urbano y de invasión, para garantizar la protección de la propiedad. Los limites establecidos para la propiedad y la zona de amortiguación deben presentarse como una modificación de los limites menores para su consideración al Comité del Patrimonio Mundial, como se solicitó en el 2012.

5. Elaborar y aplicar medidas reglamentarias y disposiciones legislativas adecuadas para gestionar las zonas de amortiguación propuestas. Estos deben incluir disposiciones claras de protección, delimitación y, en el caso de San Lorenzo, una extensión de la zona de amortiguación.

6. Aplicar un riguroso plan de topografía, estudio y cartografía arqueologica antes de intervenir para salvaguardar las condiciones de autenticidad e integridad de la propiedad y asegurar la conservación de atributos que transmitan el Valor Universal Excepcional.

7. Establecer la colaboración entre expertos interdisciplinarios internacionales para las obras de preservación en fortificaciones, teniendo en cuenta que, el Estado Parte tiene capacidades limitadas en estos campos. ${ }^{43}$

8. Los esfuerzos de colaboración deberían orientarse hacia la creación de habilidades para fortalecer las capacidades y, por lo tanto, la sostenibilidad de los esfuerzos. La misión recomienda que se formule un programa de fomento de la competencia en materia de preservación, mantenimiento y turismo cultural. El programa debe considerar el apoyo de las universidades panameñas y las instituciones internacionales especializadas en estas disciplinas.

9. Tomar medidas urgentes junto con las autoridades locales para recuperar las características naturales y del entorno. La situación actual ha causado un impacto negativo y directo en las estructuras de Santiago, Santiago de la Gloria y más, particularmente, en San Jerónimo debido a la Quebrada Guinea que ha causado la erosión y el colapso de una gran parte del muro al lado del banco. Además, también se necesitan medidas sanitarias urgentes en el pueblo (sistema de alcantarillado dañado, aguas residuales, residuos sólidos en la Quebrada Guinea o en la Babia), no sólo por razones de salud pública sino también, porque son

\footnotetext{
${ }^{43}$ Los puntos 7 y 8 han sido resaltados para evidenciar los artículos en los cuales, se fundamenta este proyecto.
} 
Invest. pens. crit. (ISSN 1812-3864)

Vol. 5, No. 1, enero-abril 2017

pp. $41-68$

factores que también contribuyen al deterioro de los cimientos de las fortificaciones construidas en el fondo marino.

10. Acelerar la reubicación de las familias que ocupan las zonas internas del castillo de Santiago de Gloria y, si es posible, de las que viven al lado de la Quebrada Guinea, a nuevas viviendas actualmente en construcción.

11. Prospeccionar y estudiar el Castillo de San Lorenzo desde el punto de vista geológico y ecológico, en particular, donde convergen el Río Chagres y el Mar Caribe. En este lugar, dos bóvedas se han visto afectadas y constituyen un área de riesgo en la actualidad.

12. Realizar un estudio sobre la corrosión de las fundaciones en contacto directo con el mar, como en la batería de San Jerónimo, y realizar investigaciones sobre las acciones emprendidas en otras fortificaciones de la región caribeña que tienen el mismo problema, como por ejemplo, la batería de San Fernando en Cartagena de Indias y el Castillo de San Juan de Ulúa en México, entre otros, para informar sobre posibles opciones de conservación.

13. Realizar estudios sobre las amenazas ambientales a la babia de Portobelo para encontrar soluciones. En espera de los resultados de estos estudios, las autoridades marítimas y turísticas y el INAC deben limitar el uso de la Babia para el turismo y la navegación.

14. Buscar financiamiento para la creación de la Oficina Técnica en Portobelo, con técnicos especializados y personal calificado en conservación, regulación urbana y ordenamiento territorial para contar con capacidad de respuesta adecuada a nivel local.

15. Promover la creación de "Guardianes del Patrimonio" con estudiantes de secundaria. Un programa propuesto consistiría en la formación sobre la conservación del patrimonio cultural y sobre Portobelo y sus fortificaciones y la obtención de empleo como guardianes y guías del lugar. Dependiendo de las habilidades, los aprendices también podrían ayudar en obras arqueológicas y de conservación. Para el caso de San Lorenzo, se podrían explorar las posibilidades de involucrar a los jóvenes más allá de los estudiantes de secundaria. Dicho programa incorporaría a los jóvenes en actividades relacionadas con el patrimonio y, en última instancia, podría conducir a una mayor capacitación en materia de conservación.

16. Promover la creación de la Escuela de Oficios para la formación de jóvenes en labores relacionadas con la conservación y restauración del patrimonio edificado: cantería, carpintería, construcción, mantenimiento y control de la vegetación y de la siderurgia, utilizando los métodos ya desarrollados por la Agencia Española de Cooperación Internacional (AECI) y modelos implementados en Cartagena de Indias, Colombia y La Habana, Cuba.

17. Realizar un estudio petrográfico de las fortificaciones de Portobelo y San Lorenzo para comprender la mineralogía y las patologías de los materiales de construcción para informar mejor las decisiones de 
Invest. pens. crit. (ISSN 1812-3864)

Vol. 5, No. 1, enero-abril 2017

pp. $41-68$

conservación de las intervenciones. Los morteros, los renderizados y los ladrillos también se incluirán en este estudio petrográfico.

18. Organizar y/o promover un congreso o reunión de expertos para evaluar los principales problemas que afectan a las fortificaciones de Portobelo y San Lorenzo. Por ejemplo, Panamá podría ser la sede de los encuentros anuales en la próxima reunión de los Comités Cientificos Internacionales de ICOMOS en Fortificaciones y Patrimonio Militar o en el Comité de la Piedra y organizar algunas sesiones de trabajo en las fortificaciones de Portobelo y San Lorenzo.

El último informe de Panamá fue presentado a UNESCO (13) en enero del 2017, donde se expone un programa detallado de medidas correctivas y de objetivos organizados y en algunos casos, ya alcanzados. El compromiso de Panamá de rescatar a las Fortificaciones de Portobelo y San Lorenzo, bienes monumentales nacionales y Patrimonio de la Humanidad, así como, el progreso de sus actividades será estrictamente monitoreado por UNESCO en un calendario a completarse entre el 2016 y el 2019. Actualmente, los Fuertes de Portobelo y San Lorenzo continúan en la Lista de Patrimonio Mundial en Peligro $(14)^{44}$.

\section{Justificación}

Las Fortificaciones de Portobelo y San Lorenzo son ejemplos únicos y representan una obra maestra del ingenio creativo humano (criterio i - inscripción UNESCO), así como, las adaptaciones posteriores de las características de su arquitectura militar a causa de nuevas estrategias defensivas y de combate y a las condiciones naturales del territorio y el clima tropical durante los siglos XVI, XVII y XVIII (criterio iv) los cuales, representan además, el desarrollo estructural y tecnológico de un sistema militar que funcionó en el Caribe.

El Centro Histórico de Portobelo, puerto de enlace en el Atlántico de Tierra Firme con la España y con el tráfico comercial y cultural con el resto de América, cuenta con condiciones históricas, arquitectónicas y paisajísticas excepcionales que a su vez, se relacionan con el carácter defensivo de sus estructuras restantes y su entorno natural, formando un único complejo patrimonial e integrado.

Los valores a proteger y conservar poseen una doble naturaleza. Por un lado, el carácter histórico de la ciudad y monumental de las fortificaciones, bienes materiales que constituyen el patrimonio arqueológico, arquitectónico, urbano y natural; y por otro lado, las tradiciones, costumbres y expresiones de los habitantes, valores simbólicos y espirituales que representan el patrimonio socio - cultural y

\footnotetext{
${ }^{44}$ Pág. 8
} 
etnoantropológico de la costa colonense. La realización estratégica del PEPC ${ }^{45}$ ha sido encaminada al desarrollo centrado e integrado hacia el patrimonio histórico - cultural, natural - paisajístico y arquitectónico - militar, puntos de fuerza de Portobelo y San Lorenzo, y religioso - cultural sólo para Portobelo.

El Plan de Estrategias es parte integrante del Plan de Gestión y del Plan Maestro, y es un instrumento para la Protección y Conservación de los Fuertes de Portobelo y San Lorenzo. En relación a los puntos 7 y 8 de las recomendaciones emitidas por ICOMOS en el informe del 2014, descritas en este documento, el PEPC de los Fuertes de Portobelo y San Lorenzo es un proyecto de la Universidad Católica Santa María la Antigua realizado por arquitectos especializados en la restauración, activos en Italia y con experiencia en el campo de las fortificaciones ${ }^{46}$ quienes, además, colaboran como profesora e investigadores en esta institución académica.

El PEPC es un instrumento orientado a:

a. La identificación de políticas que permitan la protección, conservación y revalorización de los sitios monumentales y su patrimonio arqueológico, arquitectónico, urbano y natural dentro de la comprensión de sus valores como un único patrimonio paisajístico y cultural;

b. al fortalecimiento de las capacidades en la tutela y en las intervenciones restaurativas o conservativas a través de la profundización en el conocimiento del bien monumental;

c. a la sensibilización en la investigación como un instrumento a favor de la documentación y preservación de la cultura del bien y su VUE;

d. al incentivo de las colaboraciones interdisciplinarias de expertos y de instituciones afines a la conservación del patrimonio histórico - cultural, a la educación superior y a la divulgación de sus conocimientos y productos teóricos, técnicos y científicos.

Se fundamenta en los criterios y objetivos del "Plan de Acción para el Patrimonio Mundial en América Latina y el Caribe (2014 - 2024)" (15), en el "Plan de Trabajo Regional de Cultura para América Latina y el Caribe (2016 - 2021)” (16) y en las “Directrices Prácticas para la aplicación

\footnotetext{
${ }_{4}$ Plan de Estrategias para la Protección y Conservación de los Fuertes de Portobelo y San Lorenzo

${ }^{46}$ El estudio Casini Cid Architetti con sede en Italia, es una firma dedicada a la Restauración Arquitectónica Monumental. Entre sus principales proyectos de restauración y conservación en el tema de fortificaciones, se destacan:

- Restauración del paramento de la Muralla Defensiva de la Ciudad de Lucca

- Restauración del Bastión del Bastardo y la Casa del Verdugo, Lucca

- Estudios previos y levantamiento arquitectónico de la Fortificación de Sassi, Molazzana - Lucca.
} 
de la Convención del Patrimonio Mundial” (4), que comparten una prioridad en común en el ámbito de la cultura: la protección, promoción y transmisión del patrimonio.

El Plan está dirigido hacia tres zonas de actuación: el Fuerte de San Lorenzo, el Conjunto de Fortificaciones de Portobelo y el Centro Histórico de Portobelo; cada una con necesidades distintas pero relacionadas entre sí. Las estrategias que se presentaron fueron individuadas en Estrategias de Protección y en Estrategias de Conservación.

Las bases utilizadas para la confección del PEPC han sido el conocimiento técnico y experiencia restaurativa de los autores del Plan, en fortificaciones reconocidas por su importancia como bienes monumentales del patrimonio cultural italiano; la colaboración de la "Dirección de Tutela Arquitectónica y Paesajística de la Ciudad Histórica de Lucca” de la Superintendencia para el Patrimonio Histórico, Artístico y Etnoantropológico y para los Bienes Arquitectónicos y del Paisaje de las Provincias de Lucca y Massa Carrara (17); y del estudio de Planes de Estrategias de fortificaciones relacionadas por correspondencia histórica y técnica con los Fuertes de Portobelo y San Lorenzo, según la información obtenida en la investigación histórica realizada por los autores y que sustenta los VUE inscritos de la propiedad $\mathrm{UNESCO}^{47}$.

En la definición de una política eficaz de protección y conservación de estos bienes culturales, se identificaron los siguientes Objetivos Generales del PEPC, que son:

a. La revalorización de las Fortificaciones y de sus restos arqueológicos a través de un adecuado estado de conservación que permita mantener la integridad y autenticidad de sus construcciones, un acceso peatonal y recorridos que no afecten a las estructuras, y la divulgación de su historia, características y relaciones político - defensivas para la mayor comprensión de estos bienes arquitectónicos.

b. La revalorización y recualificación del Centro Histórico de Portobelo junto con su trazado original y las edificaciones históricas civiles y religiosas que constituyen el patrimonio arquitectónico y urbano de este sitio, así como, la integración de sus tradiciones locales a través de programas que promocionen actividades académicas y eventos culturales que divulguen el patrimonio cultural del lugar y sus habitantes.

\footnotetext{
${ }^{47}$ La investigación histórica del PEPC de Portobelo y San Lorenzo está por ser entregada a las autoridades en el primer trimestre del 2017. Actualmente, en diciembre del 2016, se publicó en la Revista de la USMA: "Investigación y Pensamiento Crítico", Vol. 4, Núm. 3, la primera parte del estudio en el artículo: "Estudios de las fortificaciones italianas de época moderna. El retro tierra cultural de los ingenieros militares Antonelli, activos en Panamá".
} 
c. El reconocimiento, creación e implementación de una "tutela paisajística" inclusiva entre el "patrimonio natural" y el "patrimonio construido" que establezca los valores de pertenencia, territorialidad, interacción y de relaciones intrínsecas entre ambos tipos de patrimonios, condiciones únicas que permitieron el asentamiento y construcción de este complejo de fortificaciones, su poblado y área portuaria en las costas caribeñas de Panamá.

d. La potenciación principal de un turismo cultural, sostenible y controlado junto con actividades comerciales dirigidas al rescate del patrimonio histórico - cultural de estos sitios, cuyos beneficios económicos colaboren a la conservación de las estructuras y los VUE del conjunto de bienes monumentales de Portobelo y San Lorenzo, así como, a la obtención de una mejor calidad de vida de los habitantes del centro histórico.

e. La promoción, creación de incentivos, valorización e implementación de proyectos a través de la cooperación de entidades académicas e instituciones nacionales e internacionales reconocidas por su labor en la protección y conservación del patrimonio cultural y en la calidad de sus expertos y sus productos técnicos, científicos, de tutela y en gestión de bienes históricos.

f. La creación de incentivos para la expansión del conocimiento de los bienes monumentales, de sus características, del territorio y de sus relaciones históricas; dirigidas a documentarlos para la preservación y conservación de sus datos histórico - culturales. La profundización del conocimiento histórico, técnico y científico permitirá identificar criterios y estrategias restaurativas, conservativas y de tutela apropiadas al bien y a sus valores que contribuirán al fortalecimiento de las capacidades de los profesionales y técnicos en la edilicia colonial panameña.

g. La divulgación y promoción de los resultados de estudios y proyectos y de las experiencias en la planificación, en las intervenciones y en las excavaciones realizadas en los sitios monumentales en las diferentes áreas de interés técnico, científico, de tutela y de gestión permitirán un enriquecimiento cíclico y mejoras al sistema de planificación estatal y al de enseñanza superior en pro de la formación de profesionales y técnicos especializados panameños, comprometidos con la conservación de su patrimonio histórico y la preservación de su legado cultural.

\section{Métodos}

El PEPC de Portobelo y San Lorenzo fue enfocado hacia dos tipos de investigaciones: una, de base histórica y de comprensión cultural y técnica de los bienes monumentales; y otra, en normativas de tutela y en planificación y gestión de centros históricos y de bienes de interés cultural y de patrimonio mundial, con la identificación de criterios de protección y conservación no empleados en la legislación panameña hasta ahora. 
Invest. pens. crit. (ISSN 1812-3864)

Vol. 5, No. 1, enero-abril 2017

pp. $41-68$

La finalidad de la investigación fue de tipo básica (recopilación de datos y análisis de información) y aplicada (elaboración de un Plan de Estrategias). El enfoque del proceso de investigación desarrollado fue de tipo cualitativo donde se buscó comprender los atributos y valores originales de los Fuertes de Portobelo y San Lorenzo. El alcance de la investigación ha sido de tipo observacional y transveral: exploratorio (análisis de las estrategias militares y sus sistemas arquitectónicos y constructivos), descriptivo (explicación de las estructuras militares, su funcionamiento y relaciones), correlacional (comparación de las estructuras y sistemas de los siglos XVI, XVII y XVIII realizadas en Portobelo y San Lorenzo), causal (necesidad de información base documental y crítica que sustentase la importancia de los valores de ambos fuertes ante la UNESCO).

La investigación histórica consistió en la recopilación de datos (bibliográficos, documental, ilustrativos y de observación in situ) y en el análisis crítico de los mismos a través de un método lógico que permitierá identificar y explicar descriptivamente la comprensión de los sistemas arquitectónicos y constructivos y el funcionamiento de la edilicia militar realizada en los Fuertes de Portobelo y San Lorenzo. Se construyó una ruta de estudio a través del trazado histórico de las actividades de la familia Antonelli, concentrándonos en las figuras de Giovanni Battista, Battista y Cristoforo Rota ${ }^{48}$, desde la base familiar y el contexto natal, los lugares y fortificaciones donde mantuvieron relaciones laborativas o fueron de referencia cultural y técnica, los tratados que circulaban para la época y que fueron fuente del conocimiento teórico, hasta las figuras que fueron de influencia y finalizaron por definir la construcción del conocimiento técnico de estos tres personajes. Así como, en el caso de las estructuras del siglo XVIII proyectadas por el arquitecto militar Ignacio Sala y realizadas por el ingeniero Manuel Hernández, y la base teórica y práctica cultural de influencia española, francesa y holandesa desarrolladas y adaptadas a las condiciones del territorio panameño.

Los resultados de la investigación histórica y la profundización adquirida en el conocimiento de los bienes monumentales en estudio, sirvieron de base para la investigación normativa. Se recaudó la siguiente información:

- Los planes de tutela de algunas fortificaciones realizadas por la familia Antonelli y por otras, que según la ruta de estudio antes descrita, sirvieron de referencia para el conocimiento práctico de esta familia. En total, se estudiaron los planes de 4 fortificaciones ubicadas en Italia, España y el Caribe de las cuales, 3 son Patrimonio Mundial de UNESCO.

- Los planes de tutela UNESCO que rigen para el área de América Latina y el Caribe a los cuales, las estrategias del PEPC de Portobelo y San Lorenzo debían responder en correspondencia a la problemática actual evidenciada por ICOMOS, en su visita técnica del 2014, y por su condición de Patrimonio Mundial UNESCO.

\footnotetext{
48 Battista Antonelli y su primo Cristoforo Rota son los principales autores de las fortificaciones antonellianas en Panamá. Battista, como proyectista y estratego militar, mientras que, Cristofo como director de obras y ejecutor. Giovanni Battista Antonelli, hermano mayor de Battista Antonelli, es la influencia teórica y técnica principal de los 4 Antonelli (en orden cronológico: Battista, los 2 hermanos Garavelli Antonelli y Cristoforo Rota Antonelli) que trabajaron para él en España. Su tratado "Epitomi delle Fortificationi Moderne" dedicado a Felipe II, hace demostración del dominio en la construcción de las "fortificazioni alla moderna" o "tracé à l'italienne", en las estrategias militares de proyectación, en el funcionamiento del ataque y la defensa de los fuertes abaluartados, y en la tecnología del sistema constructivo desarrollado en Italia al inicio del siglo XVI.
} 
- Los antecedentes actuativos en la protección y conservación de las fortificaciones panameñas desde su reconocimiento legislativo como monumentos históricos de la nación hasta la fecha.

- Los antecedentes de acuerdos académicos y de instituciones internacionales reconocidas en el campo de la protección del patrimonio histórico realizados para la DNPH y el PPSL, y a través de la colaboración de profesionales especializados.

- Entrevista, análisis de la propuesta y asesoría de un especialista en el tema de la protección, conservación y restauración de sitios históricos y fortificaciones monumentales, de la "Dirección de Tutela Arquitectónica y Paesajística de la Ciudad Histórica de Lucca" de la Superintendencia para el Patrimonio Histórico, Artístico y Etnoantropológico y para los Bienes Arquitectónicos y del Paisaje de las Provincias de Lucca y Massa Carrara, en Italia.

Las visitas técnicas estuvieron dirigidas hacia las dos áreas de investigación. Por una parte, se realizó el análisis directo de los objetos (fortalezas) en estudio a través de campañas fotográficas y de mediciones puntuales in situ realizadas en Italia, España y Panamá; y se levantaron datos para la comprensión técnica y el análisis crítico y comparativo finalizado al estudio de la aplicación de prototipos y soluciones compositivas de arquitectura militar correspondientes al tema de las estrategias de defensa militar de la época, además de, la relación de los materiales constructivos, las técnicas constructivas, el funcionamiento estructural y el entorno de asentamiento. Y por la otra parte, la observación del resultado en la gestión del patrimonio tutelado visitado y sus estrategias de protección y conservación aplicadas. Se visitaron en total más de 17 estructuras fortificadas: 9 en Italia, 2 en España, el Fuerte de San Lorenzo y el Conjunto de Fortificaciones de Portobelo.

\section{Resultados y Productos}

El proyecto fue dividido en 4 etapas de desarrollo distribuidas a lo largo de un año de ejecución (12 meses). Las 3 primeras (9 meses) dedicadas en su parte inicial, a la recopilación de información histórica, normativa y de datos, y en su parte final, al análisis de los datos obtenidos para la evaluación crítica, la comprensión cultural y la comparación de las fortalezas estudiadas teniendo como referencia, los bienes monumentales de Portobelo y San Lorenzo. La última etapa (3 meses), se concluyó con la elaboración y redacción del Plan de Estrategias y de artículos que comunicaran los resultados de las investigaciones efectuadas.

Los resultados alcanzados han sido los siguientes:

- Documentación de referencia para los análisis históricos y los análisis críticos

- Material para la comprensión de la lectura constructiva

- Un documento descriptivo y explicativo por cada etapa de investigación

- Individuación de criterios y estrategias de protección y conservación

- Un documento normativo

En cuanto a los productos obtenidos, se pueden mencionar los siguientes:

- "Plan de Estrategias para la Protección y Conservación de los Fuertes de Portobelo y San Lorenzo". Documento normativo entregado formalmente a la DNPH, al PPSL y a la USMA, el 16 de enero de 2017. Un Resumen Ejecutivo en inglés, así como, el documento original 
Invest. pens. crit. (ISSN 1812-3864)

Vol. 5, No. 1, enero-abril 2017

pp. $41-68$

en español fueron incluidos en el "SOC Panama's Report 2017” (13), presentado a UNESCO a finales de enero del 2017 por las autoridades de tutela del patrimonio panameño.

- "Estudio de las fortificaciones italianas de época moderna. El retro tierra cultural de los ingenieros militares Antonelli, activos en Panamá". Artículo publicado en la Revista “Investigación y Pensamiento Crítico", Vol. 4, Núm. 3, septiembre - diciembre 2016. Págs. 74 $-117$.

- “Análisis de las Técnicas de Construcción de los Fuertes de Portobelo y San Lorenzo". Extensión del actual proyecto de investigación a través del financiamiento por SENACYT ${ }^{49}$ y a realizarse en el período 2017 - 2018.

El "Plan de Estrategias para la Protección y Conservación de los Fuertes de Portobelo y San Lorenzo", producto final y objetivo principal del proyecto de investigación, es un proyecto preliminar que identificó los siguientes tipos de estrategias ante la problemática evidenciada y definió directrices a seguir para su implementación:

Las Estrategias de Protección están dirigidas a la creación de 5 Planes de Tutela integrados y organizados de acuerdo a la individuación tipológica del patrimonio presente en el territorio de la Bahía de Portobelo y en el acceso al Río Chagres, que serán instrumentos de actuación con los cuales, iniciar un proceso de intervención sobre los bienes culturales y ambientales del lugar para el rescate de las estructuras arquitectónicas en peligro y de adecuación del territorio para que sea capaz de recibir un flujo socio - cultural, comercial y turístico apto a la conservación de la integridad de los monumentos y sus VUE. Los Planes de Tutela propuestos están orientados a la protección del Patrimonio Paisajístico, Urbano, Arquitectónico, Arqueológico y Subacuático, y al Etnoantropológico.

Otra de las Estrategias de Protección individuadas fue el Plan de Cooperación que propone el intercambio y colaboración de especialistas, de entidades académicas e instituciones nacionales e internacionales reconocidas por su labor en la protección y conservación del patrimonio cultural, para el fortalecimiento de las capacidades y la expansión del conocimiento. Los beneficiarios serán nuestras instituciones estatales encargadas de la salvaguarda del patrimonio nacional, nuestras universidades públicas y privadas en la formación de especialistas panameños, y nuestros profesionales en el campo de la tutela, gestión, restauración y conservación del patrimonio histórico y cultural.

Las Estrategias de Conservación propuestas fueron las siguientes:

1. Inventario, Clasificación y Catalogación de Bienes Inmuebles de Interés Cultural (BIC) y de Espacios Protegidos: Como medida de conservación de los bienes inmuebles o espacios de interés artístico, histórico, paleontológico, arqueológico, etnológico, arquitectónico o botánico y los que integren un ambiente característico o tradicional, así como, los que se pretendan conservar por su representatividad del acervo cultural común o por razones paisajísticas. La profundización y la difusión del conocimiento de los bienes histórico - culturales y naturales - paisajísticos a través de

\footnotetext{
${ }^{49}$ Secretaría Nacional de Ciencia, Tecnología e Innovación. Institución panameña dedicada a fortalecer, apoyar, inducir y promover el desarrollo de la ciencia, la tecnología y la innovación en el país.
} 
un sistema informativo territorial de información accesible a la globalidad del patrimonio cultural, la digitalización de documentos de interés histórico y artístico, y la difusión telemática del conocimiento es imperante cuando hablamos de bienes monumentales que son Patrimonio de la Humanidad.

2. Plan del Conocimiento del BIC: es un instrumento dedicado a la extensión del conocimiento, a la profundización de los valores histórico - culturales del BIC a través de la investigación histórica, técnica y científica, y a la sensibilización en la búsqueda de información que permita expandir datos útiles para la protección, restauración, conservación y preservación del bien histórico.

3. Plan de Valorización del Patrimonio Cultural, Ambiental y Socio - Económico: está orientado a la adecuación de la oferta de servicios culturales, de infraestructuras, de servicios de recibimiento y del conjunto de servicios territoriales cuya actividad está relacionada directa o indirectamente a las actividades de valorización.

4. Plan de Promoción, Formación y Comunicación: trabajará en conjunto con el Plan de Cooperación, el Plan de Conocimiento del BIC y con el Plan de Valorización del Patrimonio Cultural, Ambiental y Socio - Económico, con la finalidad de, fortalecer las capacidades (15) ${ }^{50}$ $(16)^{51}$ y habilidades de los profesionales panameños en las áreas especializadas de la tutela, gestión, restauración y conservación del patrimonio histórico nacional, y cumplir con los objetivos del "Plan de Acción para el Patrimonio Mundial en América Latina y el Caribe (2014 - 2024)”.

\section{Conclusiones}

La comprensión de los valores y del conocimiento cultural de un bien histórico es fundamental en la definición de estrategias de salvaguarda y valorización conscientes con lo que el monumento representa e incluye. El Patrimonio es fuente de identidad de una nación y de sus ciudadanos, y es un deber el protegerlo y respetarlo. Por esta razón, el rescate del patrimonio arquitectónico y de sus relaciones urbanas, paisajísticas y socio - culturales es la recuperación no sólo de la dignidad del bien histórico en sí, sino de todo lo que comporta e involucra para una nación.

Cuando el bien de una nación, en cambio, es reconocido como "Patrimonio Mundial", el concepto de su valor histórico y riqueza cultural se extiende y amplía:

"Valor Universal Excepcional significa una importancia cultural y/o natural tan extraordinaria que trasciende las fronteras nacionales y cobra importancia para las generaciones presentes y venideras de toda la humanidad $[\ldots] ”(5)^{52}$

\footnotetext{
${ }^{50}$ Capítulo IV - Prioridades Regionales. Punto 2 - Gestión integral del patrimonio.

${ }^{51}$ Las Areas Temáticas del Plan de Trabajo de la UNESCO. Area 2: Fortalecimiento de Capacidades y Area 3: Investigación y Sensibilización.

52 Párrafo 49
} 
Invest. pens. crit. (ISSN 1812-3864)

Vol. 5, No. 1, enero-abril 2017

pp. 41-68

Crear y reforzar las capacidades de las instituciones que protegen y administran las propiedades monumentales es una labor prioritaria, tanto como, la de impartir una formación especializada y habilitar a profesionales para intervenir en la gestión, restauración y preservación de los bienes históricos y sus valores culturales. La realización del PEPC de Portobelo y San Lorenzo ha sido una estrategia no sólo a beneficio de nuestras autoridades nacionales sino también, del fortalecimiento de las capacidades en el área de la planificación y creación de instrumentos actuativos que podrá ser utilizada en la educación superior y especializada.

\section{Agradecimientos}

- Universidad Católica Santa María la Antigua. Proyecto (SRUI-CPEI-ID-2015-2016-010) financiado a través de la Convocatoria para Proyectos de I+D 2015-2106, del Programa de Estímulo a la I+D.

- Dirección Nacional de Patrimonio Histórico. Colaboración para la Dirección Nacional de Patrimonio Histórico del Instituto Nacional de Cultura de Panamá y para el Patronato de Portobelo y San Lorenzo.

- Soprintendenza per il Patrimonio Storico, Artistico ed Etnoantropologico e per i Beni Architettonici e Paesaggio per le Provincie di Lucca e Massa Carrara, Italia. Asesoría del Ing. Francesco Paolo Cecati, Director del Ufficio Tutela Beni Architettonici e Beni Paesaggistici.

\section{Referencias}

1. Decisions adopted by the World Heritage Committee at this 36th Session. WHC-12/36.COM/19. Saint Petersburg: UNESCO, 2012. Convention concerning the Protection of the World Cultural and Natural Heritage. p. 245.

2. Report on the ICOMOS Advisory Mission to Fortifications on the Caribbean Side of Panama: Portobelo - San Lorenzo. ICOMOS. 2014. p. 65, Informe.

3. Operational Guidelines for the Implementation of the World Heritage Convention. WHC/2. s.l. : UNESCO, 1978. p. 13.

4. Decisions adopted by the World Heritage Committee at this 39th Session. WHC-15/39.COM/7A. Bonn : UNESCO, 2015. Convention concerning the Protection of the World Cultural and Natural Heritage. p. 100.

5. Operational Guidelines for the Implementation of the World Heritage Convention. WHC.15/01. Paris : UNESCO, 2015. 
6. Tejeira, Arq. Eduardo. Guía de Arquitectura y Paisaje de Panamá. Panamá : Instituto Panameño de Turismo y Junta de Andalucía, 2007.

7. Planes Portobelo y Panamá la Vieja. Gutiérrez, Arq. Samuel. 71, s.l. : Pan American Institute of Geography and History, junio 1971, Historia de América, p. 147 - 151.

8. Zapatero, Juan Manuel. Historia del Castillo San Lorenzo el Real de Chagre. Madrid : Servicio Histórico Militar del Ministerio de Defensa, 1985.

9. Decisions adopted by the World Heritage Committee at this 17th Session. WHC-93/CONF.002/14.

Cartagena : UNESCO, 1993. Convention concerning the Protection of the World Cultural and Natural Heritage. p. 111.

10. Report of the "Fortifications on the Caribbean Side of Panama: Portobelo - San Lorenzo (Panama) (C135)".

WHC-SOC-440. s.1. : UNESCO, 2011.

11. Decisions adopted by the World Heritage Committee at this 35th Session. WHC-11/35.COM/7B. Paris : UNESCO, 2011. Convention concerning the Protection of the World Cultural and Natural Heritage. p. 283.

12. Decision Report to the World Heritage Committee at 36th Session. WHC-12/36.COM/7B.102. Paris : UNESCO, May, 2012. p. 179.

13. Country Report: State of Conservation of the World Heritage Property, "Fortifications on the Caribbean Side of Panama: Portobelo - San Lorenzo (Panama) (C135)". Dirección Nacional de Patrimonio Histórico, Instituto Nacional de Cultura. Panamá : s.n., 2017. p. 174, Documento institucional.

14. Decisions adopted by the World Heritage Committee at this 40th Session. WHC-16/40.COM/7A. Istanbul : UNESCO, 2016. Convention concerning the Protection of the World Cultural and Natural Heritage. p. 82.

15. Action Plan for World Heritage in Latin America and the Caribbean (2014 - 2024). WHC-

14/38.COM/10B. Paris : UNESCO, May, 2014. Decision Report to the World Heritage Committeé at 38th Session (Annex). p. 19.

16. Plan de Trabajo Regional de Cultura para América Latina y el Caribe (2016 - 2021). La Habana, Cuba: UNESCO, 2016, Cultura y Desarrollo N¹4, p. 92.

17. Cecati, Ing. Francesco. Dirección de la Tutela Arquitectónica y Paisajística de la Ciudad Histórica de Lucca, Italia. Lucca : Soprintendenza per il Patrimonio Storico, Artistico ed Etnoantropologico e per i Beni Architettonici e Paesaggio per le Provincie di Lucca e Massa Carrara, 22 abril 2016. 
Invest. pens. crit. (ISSN 1812-3864)

Vol. 5, No. 1, enero-abril 2017

pp. 41-68

18. Country Report: State of Conservation of the World Heritage Property, "Fortifications on the Caribbean Side of Panama: Portobelo - San Lorenzo (Panama) (C135)". Dirección Nacional de Patrimonio Histórico, Instituto Nacional de Cultura. Panamá : s.n., 2016. p. 157, Documento institucional.

10 Ilustraciones (fortificaciones visitadas y estudiadas)

Fotografías por L. Casini y P. Cid

\section{ITALIA}

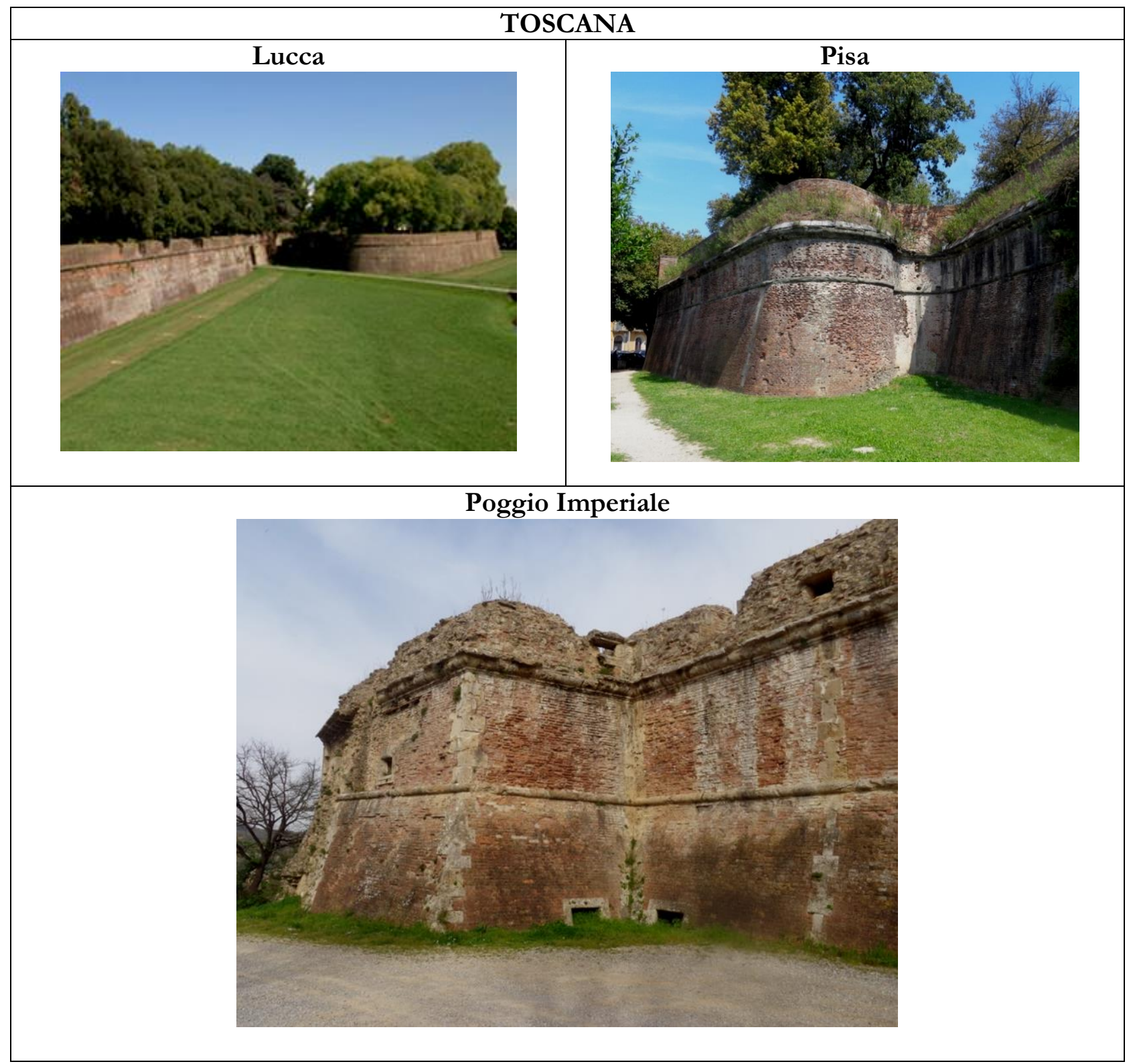


Invest. pens. crit. (ISSN 1812-3864)

Vol. 5, No. 1, enero-abril 2017

pp. 41-68

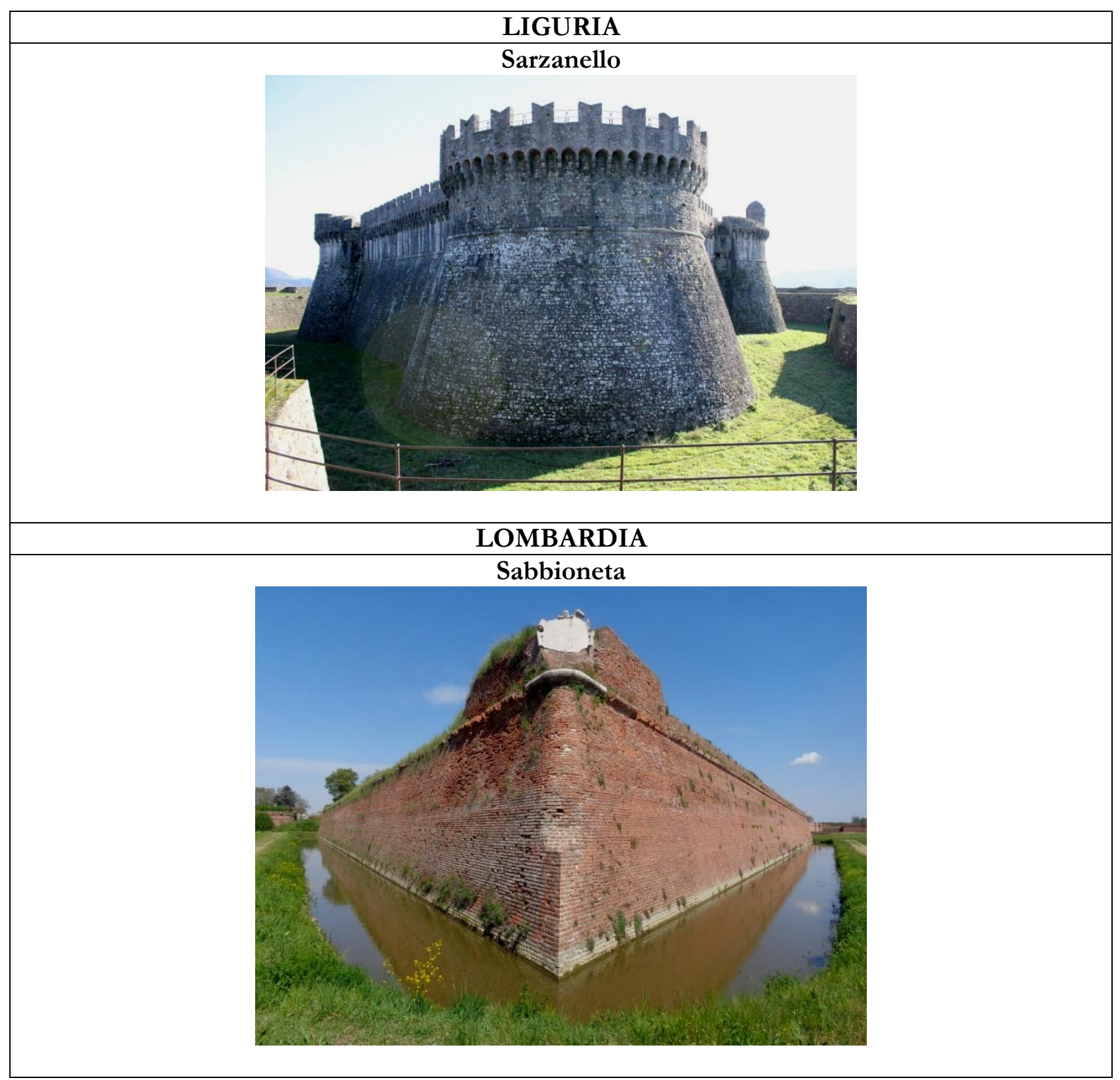



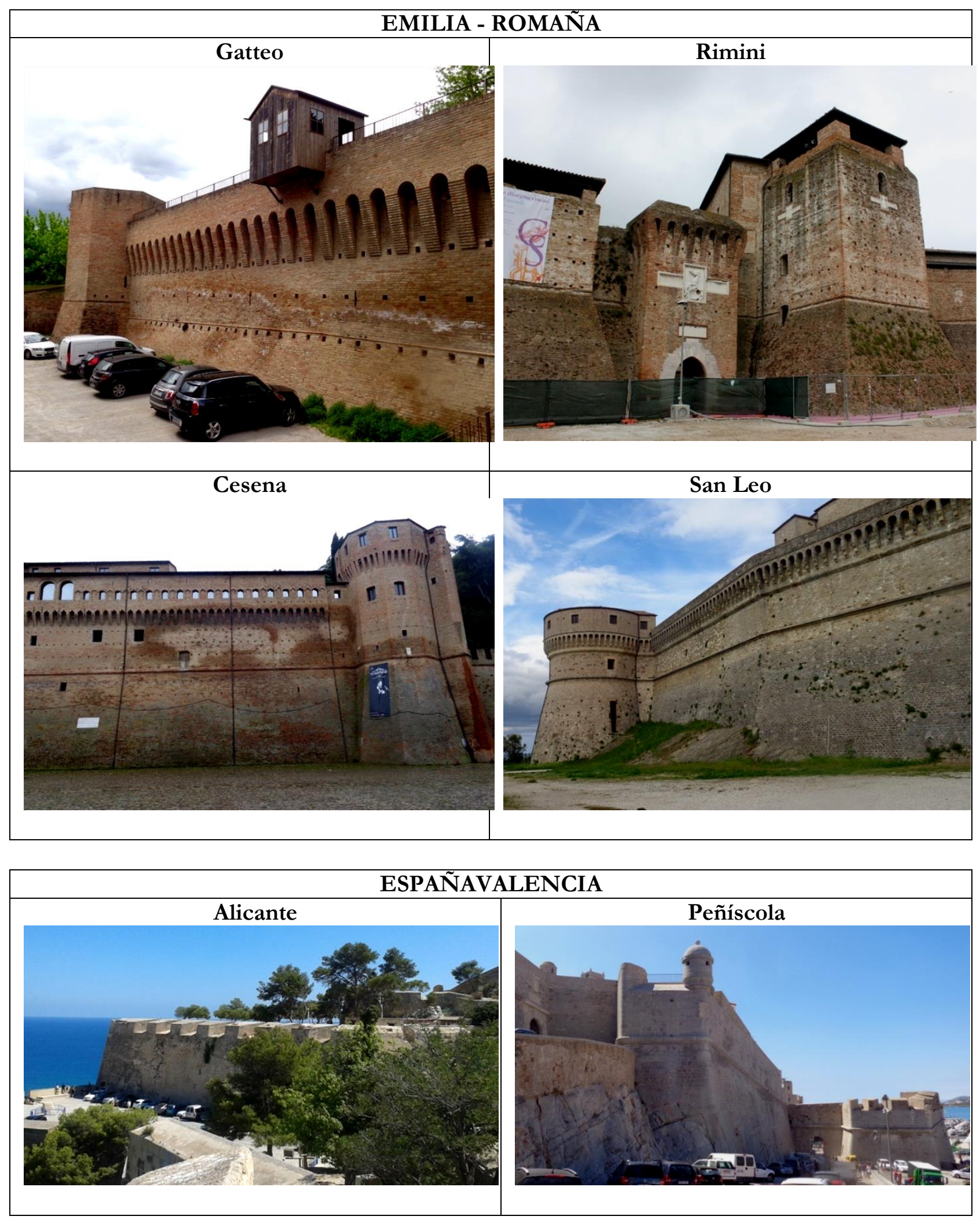
Invest. pens. crit. (ISSN 1812-3864)

Vol. 5, No. 1, enero-abril 2017

pp. 41-68

PANAMA

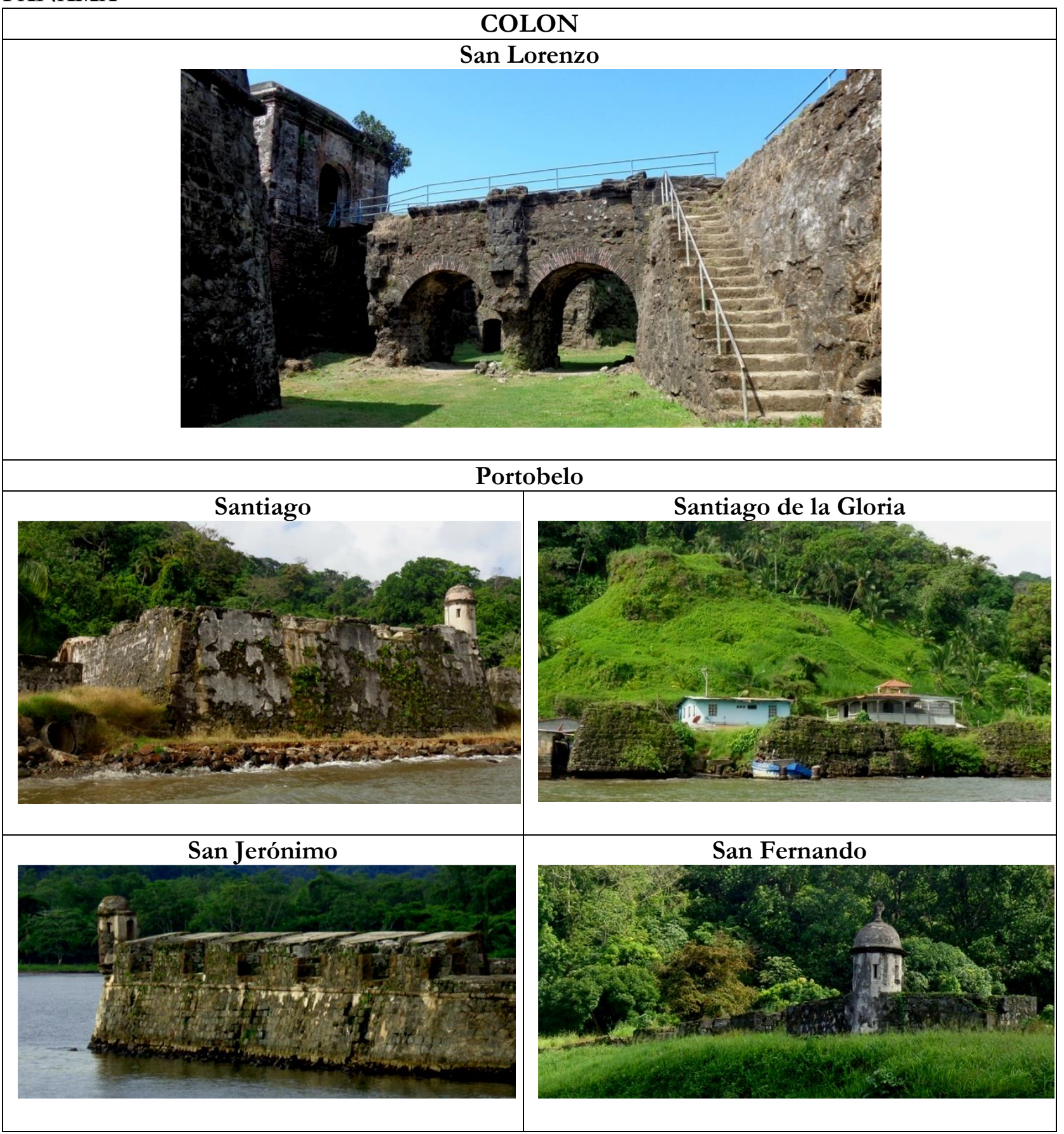

